\section{A influência da maturidade do campo institucional na legitimidade do empreendedor institucional varejista ${ }^{1}$}

\author{
André Luiz Barbosa da Silva e Juracy Parente
}

\section{RESUMO}

Este artigo tem como objetivo descrever como o grau de maturidade institucional do polo varejista de rua pode influenciar na construção da legitimidade do empreendedor institucional varejista (EIV's). O estudo está fundamentado na abordagem qualitativa com estudo de caso múltiplo envolvendo empreendedores institucionais no projeto de revitalização, totalizando oito polos varejistas brasileiros. A pesquisa contribui para o campo da Teoria Institucional, mais precisamente a vertente do empreendedorismo institucional ao demostrar que diferentemente da Teoria existente, os resultados demostram que mesmo seguindo os preceitos teóricos propostos para construção da legitimidade, os empreendedores institucionais não conseguiram realizá-la. Isso correu em decorrência das características do campo "pré-emergente" que não apresentou um grau mínimo de institucionalização necessária para garantir a atuação integral do empreendedor institucional varejista no processo de revitalização. Desta forma, a pesquisa reforça que, além de apresentar comportamentos de empreendedores institucionais e possuir um projeto relevante em benefício dos atores, deve-se analisar antecipadamente a maturidade do campo e perfil dos atores para posteriormente delinear estratégias de construção de legitimidade.

Palavras-Chave: empreendedorismo institucional; legitimidade; maturidade de campos insitucionais; polos varejistas de ruas.

The influence of the institutional field maturity on the legitimacy of the institutional entrepreneur

\section{ABSTRACT}

This article aims to define how the degree of institutional maturity of the corrected street pole can construct the appropriate institutional entrepreneur's legitimacy (IEL's). The study is based on the qualitative approach with a multiple case study involving institutional entrepreneurs in the revitalization project, totaling eight Brazilian retail centers. The research contributes to the field of Institutional Theory, more precisely the aspect of institutional entrepreneurship, by demonstrating that, unlike the existing Theory, the results show that even when following the theoretical precepts proposed to build legitimacy, the institutional entrepreneurs could not carry it out. This happened due to the characteristics of the "pre-emergent" field, which does not have the minimum necessary degree of institutionalization to guarantee the institutional entrepreneur's full performance in the revitalization process. In this sense, the research reinforces that, besides presenting the behavior of institutional entrepreneurs and having a relevant project for the benefit of the actors, one should analyze the maturity in advance.

Keywords: institutional entrepreneurship; legitimacy; maturity of institutional fields; street retail districts.

1 Gostaríamos de agradecer aos avaliadores anônimos deste artigo pelos seus comentários e sugestões por enriqueceram e contribuírem significativamente para a versão final do artigo.
Recebido em: 29/12/2019 Revisado em: 28/05/2020 Aprovado em: 16/11/2020

Check for updates

André Luiz Barbosa da
Silva iD,
Universidade Federal de Goiás, Brasil
Doutor em Administração de
Empresas, Escola de Administração
de Empresas de São Paulo, Fundação
Getúlio Vargas, Brasil
andre_luiz_b_silva@hotmail.com
Juracy Parente iD,
Escola de Administração de Empresas
de São Paulo, Fundação Getúlio
Vargas, Brasil
Doutor em Administração, University of
London, England




\section{Introdução}

Empreendedores institucionais são atores que alavancam recursos para resolver problemas propagando novos arranjos institucionais ou transformando os existentes para criar valor por meio de suas inovações (Battilana, Leca, \& Boxenbaum,2009; David, Sine, \& Haveman, 2013; Fligstein, 1997; Maguire, Hardy, \& Lawrence, (2004); Rao, Morrill, \& Zald, 2000). Como os empreendedores institucionais difundem novas ideias, o tema tem atraído atenção de pesquisadores (Battilana et al., 2009; David et al., 2013; Jayanti \& Raghunath, 2018). Assim, para construir uma nova forma organizacional se torna necessário aos empreendedores institucionais a mobilização entre os atores, atrelando condições mínimas de institucionalização do campo (Fligstein, 1997; Greenwood \& Suddaby, 2006; Hardy \& Maguire, 2008; Maguire et al., 2004). Caso contrário, o empreendedor institucional pode sofrer fortes influências na sua legitimidade em razão da baixa institucionalização.

Embora a literatura relacionada ao empreendedorismo institucional tenha apresentado crescimento, ainda faltam pesquisas com abordagens mais detalhadas sobre a atuação dos empreendedores institucionais em processos de desinstitucionalização das práticas vigentes do campo institucional, e como o grau de maturidade do campo institucional pode influenciar na sua construção da legitimidade do empreendedor institucional para iniciar novos arranjos organizacionais. Em outras palavras, as pesquisas sobre empreendedores insitucionais se apresentam como foco central na atuação na identificação de oportunidade (Buhr 2012; Greenwood, Suddaby, \& Hinings 2002; Stål, Bonnedahl, \& Eriksson, 2014), nas motivações relacionadas (Dorado, 2013), além da construção de novos contextos institucionais alinhados à maturidade do campo (Greenwood \& Suddaby, 2006; Maguire et al., 2004; Smith, Hoersch, \& Gordon,1995). Estudos realizados sobre esse tema também estão concentrados na adoção e difusão dessas novas práticas interpostas por parte dos empreendedores institucionais (Ahrens \& Ferry 2016; Van Bockhaven, Matthyssens, \& Vandenbempt 2015; Qureshi, Kistruck, \& Bhatt; 2016).

Em particular e, com os holofotes deste estudo direcionados à temática em epígrafe, nota-se uma escassez na literatura também sobre como o empreendedor institucional conduz um processo de desinstitucionalização do campo por meio da sua legitimidade. Entretanto, constatou-se a presença de pesquisas sobre fatores que a desencadeiam (Ahmadjian \& Robinson, 2001) e como geram janelas de oportunidades para o surgimento e engajamento do empreendedor (Buhr, 2012; Dorado, 2013). Muito embora também esteja comprovado que pesquisadores prestaram menos atenção na forma como a maturidade do campo influencia na construção da legitimidade do empreendedor institucional e nas suas práticas de desinstitucionalização, ao se deparar com a agenda de mudanças, tendo em mente que a legitimidade é considerada um elemento essencial para o empreendedor institcuional. Essa, caracteriza-se como chave-mestra da geração de mudança institucional (Aldrich \& Fiol, 1994; Rao et al., 2000; Suddaby \& Greenwood, 2005; Zelditch, 2001). 
Nesta circunstâncias, emerge o principal questionamento desta pesquisa que é descrever como empreendedores institucionais constroem a sua legtimidade para iniciarem o processo de desinstitucionalização das práticas vigentes e como o grau de maturidade do campo pode influênciar nesse processo. A pesquisa aborda essa questão, mas também destacamos dimensões que podem interferir na legitimidade do empreendedor institucional, como a sua posição no campo institucional, por exemplo (Boxenbaum, 2004), a argumentação utilizada entre seus pares como estratégia de convencimento para novas práticas (Boxenbaum \& Battilana, 2005; Holm, 1995; Seo \& Creed, 2002), suas formas de articulação (Clemens \& Cook, 1999) e as percepções sobre a sua construção da legitimidade (Garud, Jain, \& Kumaraswamy, 2002; Lawrence, Hardy, \& Phillips, 2002). Essa análise é importante porque a ausência ou a baixa legitimidade do empreendedor institucional, quando reconhecida pelo campo institucional e seus atores, pode impedir a sua atuação na busca de novos arranjos organizacionais, impedindo ou dificultando o processo de desinstitucionalização.

Pode-se notar que esses estudos possuem como objetivo comum ampliar o conhecimento sobre a atuação do empreendedor institucional. Sendo assim, nesta pesquisa propomos como objetivo principal descrever como empreendedores institucionais varejistas (EIV's) constroem a sua legtimidade para desinstitucionalizar as práticas vigentes dos polos varejistas para executarem o processo de revitalização das ruas e como a maturidade desses polos podem influenciar nesse processo. Os polos varejistas de rua assumem um papel relevante na vitalidade das cidades. No entanto, devido às mudanças de mercado e a rápida expansão de concorrentes diretos, sua sobrevivência vem sendo ameaçada. Uma das estratégias empregadas no intuito de tentar reverter esse processo é representada por intermédio de projetos de revitalização fundamentados na proposta de elevar a atratividade dos polos de ruas (Balsas 2000; Cook 2009; Page \& Hardyman 1996; Teller 2008; Teller, Elms, Thomson, \& Paddison 2010; Teller \& Reutterer, 2008)

Assim, essa abordagem contribui com o cenário do empreendedorismo institucional apresentando três contribuições tidas e respeitadas como principais, a começar pela apresentação de quais características do campo institucional puderam influenciar a construção da legitimidade do empreendedor institucional varejista; em segundo plano, propõe-se apresentar os principais resultados do projeto de revitalização, alcançados pelos empreendedores institucionais após conseguirem estabelecer um estoque mínimo de legitimidade; e, por fim, munir-se da faculdade de descrever como o campo pode descontruir a legitimidade do empreendedor institucional.

\section{O processo de desinstitucionalização do campo}

A Teoria Institucional propõe explicar como as estruturas institucionalizadas, de diferentes formatos e significados, são capazes de afetar os processos organizacionais (Greenwood \& Suddaby, 2006). Tendo em 
vista que as pesquisas abordaram como as organizações se comportam face às prescrições institucionais impostas pelo campo (Tolbert \& Zucker, 1983), tais comprovações acabam por influenciar as práticas das organizações e moldam a sua estrutura e posicionamento no mercado. Cabe ressaltar que as práticas institucionalizadas propõem, como fundamentação e base de sustentação, três pilares representados pelos modos - regulativo, normativo e cognitivo - conforme propõe Scott (2008), ao afirmar que é por intermédio desses elementos que a legitimidade é estabelecida e a conformidade é assegurada.

As formas e práticas organizacionais são institucionalizadas à medida que os atores consideram adequadas às exigências técnicas da tarefa e não porque estiveram atreladas à ordem racional (Davis, Diekmann, \& Tinsley,1994). Não obstante, esses atores devem seguir esquemas que são compartilhados pelo campo institucional, podendo ser mudados sempre que as organizações julgarem conveniente. Com o avanço da estruturação de um campo organizacional, o efeito de agregação de mudanças individuais tenderá a diminuir o grau de diversidade dentro do campo (DiMaggio \& Powel, 1983), ajudando a reproduzir comportamentos mais padronizados (Scott, 2008). Esses pilares poderão assumir uma posição dominante, porém convergente entre os três (Wicks, 2001). Todavia, essa estabilidade não impede que as mudanças do campo institucional gerem um desalinhamento desses pilares (Caronna, 2004), fomentando, assim, os processos de desordem (Ahmadjian \& Robinson, 2001) e criando, portanto, uma abertura para processo de desinstitucionalização.

A desinstitucionalização refere-se à erosão ou descontinuidade de uma atividade ou prática organizacional institucionalizada (Oliver, 1992; Scott, 2008). Para que isso ocorra, novas práticas não podem ser adotadas, a menos que as antigas sejam deixadas para trás e uma compreensão mais completa das mudanças organizacionais e econômicas acabem por exigir maior entendimento de como as práticas institucionalizadas corroem e dão lugar às inovações (Ahmadjian \& Robinson, 2001). Frente ao exposto, compreende-se que as estruturas organizacionais são transformadas pela desinstitucionalização e possibilitam abertura para adoção de uma nova legitimidade, sendo um elemento essencial para o desenvolvimento e criação de novas formas organizacionais (Aldrich \& Fiol 1994; Dacin, Goodstein, \& Scott, 2002). As organizações precisam buscar legitimidade por meio da formação do ambiente institucional (Dowling \& Pfeffer, 1975), no intuito de obterem acesso aos recursos, de forma a garantir a sua sobrevivência (Meyer \& Rowan 1977; Ruef \& Scott 1998; Singh, Tucker, \& House 1986; Zimmerman \& Zeitz 2002; Zucker, 1987).

Essa construção da legitimidade é capaz de resistir a desafios, sustentando a nova instituição e evidenciando a sua adequação à ordem natural do campo, caso contrário, sem essa legitimidade, a nova instituição torna-se vulnerável, o que pressupõe a necessidade de uma base para a desinstitucionalização (Davis et al., 1994). Para que isso ocorra e traga ao contexto resultados satisfatórios, os atores precisam percorrer duas trajetórias. A primeira é assumir posições não-dominantes desde que construam a sua legitimidade, no intuito de avançarem na desconstrução da estrutura vigente, mobilizando outros atores mediante a apresentação de sua 
agenda de mudança, uma vez que esses campos em formação fornecem um foco de atenção comum e servem para interconectar atores diferentes em um único campo (Anand \& Peterson, 2000). Tais projetos são munidos de uma abordagem inovadora e constituem a base para essa compreensão, bem como para que surjam novos entendimentos e ações que, por sua vez, mudem o contexto institucional existente (Hargadon \& Douglas, 2001). Como segunda trajetória, por sua vez, é exigido um elevado grau de esforço para romper a oposição de atores internos ao campo, cujos interesses são ameaçados por essa nova abordagem institucional. Desta forma, é relevante compreender como os atores, amparados na sua legitimidade, tentam propor mudanças institucionais, atendo-se à forma como o campo responde à proposta de desinstitucionalização.

\section{- A influência do grau de maturidade do campo institucional na legitimidade do empreendedor institucional}

Introduzir o processo de desinstitucionalização, em sistemas sociais, compreende uma atividade arriscada, mas é exatamente o que fazem os empreendedores institucionais ao atuarem na criação de novas experiências, fazendo prevalecer a transformação anteriormente realizada em instituições (Battilana et al. 2009; Garud, Hardy, \& Maguire 2007; Maguire et al., 2004) e podendo atuar de forma individual ou grupos de atores e organizações (Garud et al. 2002; Greenwood, Suddaby, \& Hinings, 2002; Maguire et al., 2004). Algumas das características são necessárias para serem considerados empreendedores institucionais, como a participação ativa predisposta a gerar mudanças, mobilização constante, liderança e articulação, a fim de poder angariar recursos destinados à implementação de novas estruturas institucionais (Battilana et al., 2009; Boxenbaum, 2004; Greenwood \& Suddaby, 2006).

Para Battilana et al. (2009) os atores devem preencher duas condições para serem considerados empreendedores institucionais: (1) iniciar mudanças divergentes e (2) participar ativamente na implementação dessas mudanças. Por isso, Els devem localizar as suas ideias dentro do conjunto de entendimentos e ações existentes, que constituem o ambiente institucional, e ainda definir as suas inovações que vão além das existentes (Hargadon \& Douglas, 2001), de modo a propor divergências que rompem com o modelo institucionalizado dentro de um determinado contexto (Amis, Slack, \& Hinings, 2004; Garud et al., 2002; Greenwood \& Hinings 1996; Lawrence et al., 2002), buscando, assim, a desinstitucionalização. Ou seja, os campos em que os empreendedores institucionais realizam manobras variam em seu nível de maturidade (David et al., 2013). Nesse contexto, suas estratégias podem ser distintas quando posicionadas em campos ainda em formação, mesmo que na condição de estáveis ou em crise (Fligstein, 1997).

Pode-se tomar como exemplo algumas situações ocorridas em campos maduros quando as interações e rotinas são estabelecidas entre os participantes dotados de forte consciência de suas posições no contexto 
organizacional e que as relações de poder e as coalizões são definidas e alinhavadas ao objetivo comum (DiMaggio \& Powel, 1983; Fligstein \& McAdam, 2011; Greenwood \& Suddaby, 2006; Hoffman, 1999). Campos em declínio ou em crise podem ser oriundos da convivência social. Já a ruptura tecnológica, a descontinuidade competitiva e as mudanças regulatórias são capazes de perturbar o consenso construído socialmente, no terreno, convidando os protagonistas à introdução de novas ideias (Battilana et al., 2009; Greenwood et al., 2002; Holm, 1995); ou ainda, quando os atores dominantes em uma arena começam a falhar, seja por invasão ocasionada por grupos de outros campos, o fracasso organizacional dentro do próprio campo ocorre, ou ainda, fatores exógenos (Fligstein \& Mara-Drita 1996; Fligstein \& McAdam 2011).

Em campos emergentes, sugere-se que, embora os membros reconheçam algum grau de interesse mútuo, mas com a existência de pouca ação coordenada entre eles (Maguire et al., 2004), o empreendedor institucional precisa encontrar um terreno comum e elaborar um discurso abrangente, que interaja positivamente e em conformidade com os interesses e valores desses diferentes atores (Battilana et al., 2009; Fligstein, 1997), ainda que façam parte deste novo campo proposto (Rao et al., 2000). O grau de institucionalização do campo, assim como o seu grau de maturidade, pode influenciar diretamente na formação dos empreendedores institucionais, influenciando no seu desempenho e na busca de novas estruturas institucionais (Battilana et al., 2009; Tolbert \& Zucker, 1983). Para garantir a sua atuação, o campo deve demostrar um grau mínimo de institucionalização (Fligstein, 1997; Greenwood \& Suddaby, 2006; Maguire et al., 2004), caso contrário, a sua legitimidade poderá ser questionada e agravada pela ausência de modelos claramente definidos (Déjean, Gond, \& Leca, 2004). Em consequência disto, tendem a afetar o acesso do empreendedor a recursos e a sua capacidade de unir diversas partes interessadas (Aldrich \& Fiol 1994; Battilana et al., 2009; Maguire et al., 2004; Zelditch 2001).

A legitimidade é um fator de estabilidade (Aldrich \& Fiol, 1994; Zelditch, 2001) para o empreendedor institucional; é um componente chave da mudança (Aldrich \& Fiol, 1994; Suddaby \& Greenwood, 2005; Zelditch, 2001). Além disso, o empreendedor possui condições de mobilizar a legitimidade no campo (Rao et al., 2000), juntamente com os outros atores, na busca de gerar tensão focada na legitimidade de um arranjo institucional vigente (Leca, Battilana, \& Boxenbaum 2008; Seo \& Creed, 2002). O propósito dessa ação é reforçar as falhas das práticas institucionalizadas e demostrar que o novo projeto institucional trará resultados superiores, a fim de unir os considerados mais aliados, diminuindo as contradições entre os atores no campo (Boxenbaum \& Battilana, 2005; Fligstein, 1997; Greenwood \& Suddaby, 2006; Holm, 1995). Por essa razão, vale ressaltar que a maturidade do campo e o seu grau de institucionalização influenciam a legitimidade do empreendedor institucional e a sua estratégia de atuação. A pesquisa realizada por David et al. (2013) reforça esse conceito, ao demonstrar como emprendedores institucionais atuaram de forma distinta em campos emergentes e maduros para estabelecerem novas práticas organizacionais por meio da sua legitimidade ao longo do tempo. 
Em relação aos campos maduros, o empreendedor institucional deve enquadrar os seus discursos, no intuito de ressoar conforme os interesses e valores dos membros da coalização dominante (Greenwood et al., 2002; Leca et al., 2008; Suddaby \& Greenwood, 2005), cuja proposta é aumentar a ressonância da mudança a ser implantada no campo. Agora, diante do estágio de declínio, os atores apresentam um interesse coletivo e, mesmo assim, poderão encontrar soluções otimizadas, pois continuam em um campo sem regras estabelecidas capazes de contribuir com a estabilização de suas interações e, assim, alcançar a cooperação (Fligstein \& Mara-Drita, 1996) que resulte na construção da legitimidade (Phillips, Lawrence, \& Hardy 2004). Em campos emergentes, os EIV's precisam legitimar a nova estrutura institucional, juntamente com os demais atores que dependem deste campo (Aldrich \& Fiol, 1994; Koene, 2006). A estratégia de discurso entre El e campo é essencial, pois carece de gerar essa nova institucionalização (Phillips et al., 2004). Entretanto, requer que seja explorada a retórica fundamentada na novidade em processo de planejamento e construção (Zimmerman \& Zeitz 2002). Nesse formato, o apoio deve ser construído com diversos atores, evitando-se restrições, uma vez que tal atitude poderá aumentar a sua legitimidade no campo (Battilana et al., 2009; Maguire et al., 2004).

Além disso, os empreendedores institucionais podem potencializar, de outras formas, a sua legitimidade nesses campos. Um exemplo disso, é o fato que se dá pelo vínculo da causa à sua identidade (Wade-Benzoni et al., 2002), o que fará surgir filiações com outros atores na busca de empréstimo de legitimidade a outros atores vinculados (Battilana et al., 2009; David et al., 2013), ou, então, sair em busca de legitimidade externa com uma autoridade formal intencionada a validar o seu discurso de mudança (Fligstein 1997; Maguire et al., 2004; Phillips, Lawrence, \& Hardy 2000). Desta maneira, conclui-se que o empreendedor institucional deve sempre buscar o alinhamento da sua proposta institucional, os atores, a sua legitimidade e o grau de institucionalização do campo, a fim de poder avançar na construção de novas instituições.

\section{Breve contextualização do surgimento dos ENV's}

Os polos varejistas de rua assumem um papel relevante na vitalidade das cidades. No entanto, devido às mudanças de mercado e a rápida expansão de concorrentes diretos, sua sobrevivência vem sendo ameaçada. Uma das estratégias empregadas no intuito de tentar reverter esse processo é representada por intermédio de projetos de revitalização fundamentados na proposta de elevar a atratividade dos polos de ruas. No Brasil, diferentemente do contexto internacional, não existe um modelo institucionalizado resguardado por uma legislação específica que permita uma articulação e mobilização coesa para o processo de revitalização, viabilizando uma interação positiva entre o setor público e o privado. Em alguns estados brasileiros, algumas iniciativas surgiram em razão de inquietações de alguns varejistas e/ou organizações externas ao campo. Esses líderes varejistas se transformaram em empreendedores institucionais (El), pois assumiram a condição de atores imbuídos de fortes esforços, a fim de modificar e 
estruturar o campo organizacional para os polos varejistas de rua. Frente a esse esforço, esses varejistas precisaram construir a sua legitimidade entre os seus pares e, posteriormente, com instituições externas, caso contrário, não conseguiriam propor a desinstitucionalização das estruturas vigentes em busca de novas formas organizacionais.

Para dar início aos projetos de revitalização das ruas, os empreendedores institucionais varejistas foram convocados por instituições externas ao seu campo para atuarem de maneira direta nesse contexto. O primeiro surge pela convocação de instituições legitimadas no campo, tais como o Sebrae, a Associação Comercial ou Rede de Comunicação. Os varejistas foram então selecionados conforme o critério estabelecido por essas instituições, para que fosse possível que atuassem como empreendedores institucionais. Essa diferença entre os convocados e os espontâneos gerou impactos diretos nos resultados da revitalização, assunto a ser exposto posteriormente.

Neste sentido, verificou-se que o ato de reverter um processo de declínio e elevar a atratividade local das ruas percorreu várias etapas similares, tais como: a construção de um projeto, alianças com o setor público, a execução e o acompanhamento das obras. Em em todos os casos verificou-se particularidades, porém estas foram direcionadas a avançar na construção da sua legitimidade, o que fez clarificar, posteriormente, impactos nesse processo moderados pela maturidade institucional dos polos varejistas.

\section{- Procedimentos metodológicos}

Esta pesquisa está fundamentada em estudo de caso múltiplo e de ordem qualitativa (Eisenhardt, 1989), cujo foco é descrever como o grau de maturidade dos polos varejistas de ruas influenciou na construção da legitimidade do empreendedor institucional varejista em projetos de revitalização de ruas. As unidades de análise da pesquisa contemplaram oito polos varejistas de ruas brasileiros localizados no estado de São Paulo, Paraná, Santa Catarina, Minas Gerais e Alagoas. A proposta em selecionar os polos varejistas de ruas ocorreu mediante a possibilidade em descrever como empreendedores institucionais varejistas construiram sua legtimidade ao longo do processo de revitalização. As regiões investigadas foram selecionadas em parceria com Sebrae Nacional. Essa instituição passou pelas principais ruas brasileiras que do projeto de revitalização.

Ao analisar os diversos casos, a unidade de pesquisa baseou-se no próprio empreendedor institucional varejista, e não na participação de outros atores no campo, a fim de investigar a construção da sua legitimidade ao propor a desinstitucionalização da estrutura vigente dos polos de ruas, cujo propósito é atingir certo grau de avanço no projeto de revitalização.

\section{Seleção dos casos}

Para poder entender melhor como EIV's atuaram no projeto de revitalização de ruas, optou-se pelo estudo de caso múltiplo (Eisenhardt, 1989; Yin, 2009) de forma a diferenciar-se de estudos de caso único, aplicando amplamente no 
contexto do empreendedor institucional. Compreende-se que casos múltiplos permitem maior comparação e demostram variabilidade, o que resulta na amplitude de resultados (Benbasat, Goldstein, \& Mead 1987; Pettigrew, 1987; Yin, 2009). Neste sentido, foram selecionados oito polos varejistas de ruas, conforme Quadro 1, com apresentação de estágios distintos no processo de revitalização, o que significa combinar diversas atuações do empreendedor institucional varejista no processo de desinstitucionalização da estrutura vigente, combinada com a influência do campo na construção da sua legitimidade presente no projeto de revitalização.

Dos oito polos varejistas pesquisados, cinco conseguiram percorrer efetivamente o processo de revitalização e três apresentam-se em fase de execução. Os EIV's desempenharam papéis relevantes nesse projeto, aplicando diversas estratégias para a construção da sua legitimidade, além de apresentarem especificidades em seus comportamentos referentes a tal conquista. Desta forma, a investigação desses casos abre caminhos para novas ideias e linhas de estudo direcionados à busca de novas oportunidades que enfrentam os empreendedores institucionais em campos dessa categoria.

Quadro 1. Casos de revitalização de rua

\begin{tabular}{cccc}
\hline Caso & Estado & Cidade & Nome do polo A \\
\hline C1 & SP & São Paulo & Rua João Cachoeira \\
C2 & SP & São Paulo & Rua Oscar Freire \\
C3 & PR & Curitiba & Rua Riachuelo \\
C4 & SC & Florianópolis & Rua Vidal Ramos \\
C5 & Ubá & Rua São José \\
C6 & AL & Arapiraca & Rua Anibal Lima \\
C7 & PR & Londrina & Rua Sergipe \\
C8 & PR & Maringá & Rua Santos Dumont \\
\hline
\end{tabular}

Fonte: Elaborado pelos autores

\section{Coleta de dados}

O estudo de caso múltiplo baseou-se em quatro fontes principais de pesquisas, tais como: entrevistas, observação, análise documental e dados secundários da web, vinculados aos projetos de revitalização de cada rua. Inicialmente foram solicitados ao Serviço Brasileiro de Apoio às Micro e Pequenas Empresas (Sebrae) documentos dos locais dos polos varejistas que possuíam relação com o processo de revitalização de rua. Os relatórios disponilizados demostravam pesquisas relacionadas a percepção dos consumidores, censo dos varejistas locais ou evidenciavam as etapas do processo de revitalização. Além disso, foram coletados dados de artigos de revistas, internet e jornais, com o propósito de se aprofundar sobre o processo de revitalização. As observações ocorreram em dois polos varejistas localizados na cidade de São Paulo e foram compostas por notas de campo acompanhadas de dez visitas, de modo a verificar os resultados da revitalização, conforme Quadro 2: 
Quadro 2: Caracterização da coleta de dados

\begin{tabular}{|c|c|}
\hline Fonte de pesquisa & Caracterização da coleta \\
\hline Entrevista & $\begin{array}{l}17 \text { empreendedores insitucionais varejistas foram entrevistados, totalizando aproximadamente } 20 \text { horas de } \\
\text { gravação. }\end{array}$ \\
\hline \multirow[t]{2}{*}{$\begin{array}{l}\text { Análise documental } \\
\quad \text { e web }\end{array}$} & $\begin{array}{l}\text { Foram analisados } 35 \text { documentos referentes ao contexto de revitalização de polo varejista de ruas. Nesse total, } \\
\text { dois relatórios, especificamente, foram cedidos pelo Sebrae local. } 0 \text { primeiro relatório apresenta resultados } \\
\text { que avaliaram as características e o perfil do grupo de empresas/empreendedores representativos do público- } \\
\text {-alvo a partir das percepções do grupo de empresas participantes do projeto de revitalização. } 0 \text { segundo } \\
\text { apresentava o processo de revitalização, visando demostrar o resgate histórico da rua e demostrou o processo } \\
\text { específico da reforma da rua. }\end{array}$ \\
\hline & $\begin{array}{l}\text { Foram coletadas } 15 \text { reportagens da internet que divulgaram notícias sobre processo de revitalização das ruas. } \\
\text { As reportagens demostravam a importância da revitalização para vitalidade das ruas. }\end{array}$ \\
\hline \multirow[t]{2}{*}{ Observação } & $\begin{array}{l}\text { Foram realizadas observações em duas ruas de São Paulo (C1 e C2) totalizando dez visitas. Nesse processo } \\
\text { de coleta a observação buscou descrever três temáticas principais: fluxos de consumidores, infraestrutura e } \\
\text { perfil dos varejistas. }\end{array}$ \\
\hline & A análise da observação gerou 19 páginas de de anotações. \\
\hline
\end{tabular}

Fonte: Elaborado pelos autores

As entrevistas foram realizadas, em profundidade e para construção do roteiro de entrevistas utilizando temáticas derivadas da abordagem teórica (conforme já apresentado nesta pesquisa), sendo dividida em três partes: (1) as formas como empreendedores institucionais varejistas iniciaram o processo de desinstitucionalização; (2) as estratégias para construção da sua legitimidade; (3) como a maturidade do campo institucional dos polos varejistas influenciaram este processo ao longo do projeto de revitalização. Entrevistou-se, pelo menos, um empreendedor institucional varejista de cada polo selecionado. Buscou-se entrevistar empreendedores que participaram ativamente no processo de revitalização, a fim de obter uma gama de opiniões sobre as características institucionais dos polos varejistas, a considerar o quanto foram capazes de influenciar na legitimidade dos EIV's. A entrevista consistia em responder aproximadamente quarenta perguntas abertas. Além disso, visou-se também aplicar questões inesperadas e que surgiram no decorrer das entrevistas, agregando novas abordagens à pesquisa. No total, foram entrevistados dezessete empreendedores institucionais varejistas, totalizando mais de 20 horas de gravações que, posteriormente, foram transcritas e codificadas, além de garantir o anonimato dos entrevistados mediante a utilização de códigos individualizados de acordo com cada caso, conforme Quadro 1. Cabe ressaltar que a triangulação dos dados permitiu reduzir os riscos de interpretações incoerentes ou imprecisas, além de garantir maior validade (Denzin \& Lincoln 1994; Guba \& Lincoln 1994; Pettigrew 1990).

\section{Análise dos dados}

A análise dos casos percorreu três fases: (a) condensação de dados, (b) apresentação e elaboração de dados e (c) verificação de conclusões (Miles \& Huberman, 1994), conforme mostra a Figura 3. Para avançar nas análises, 
esta pesquisa utilizou o software NVivo 11, o que permitiu maior organização das entrevistas e, posteriormente, as suas respectivas codificações. Ao selecionar essa abordagem, viu-se, de forma clara, a validação de determinadas indicações propostas pela literatura sobre construção da legitimidade do empreendedor institucional, mas também possibilitou a geração de novas categorias, ainda não exploradas.

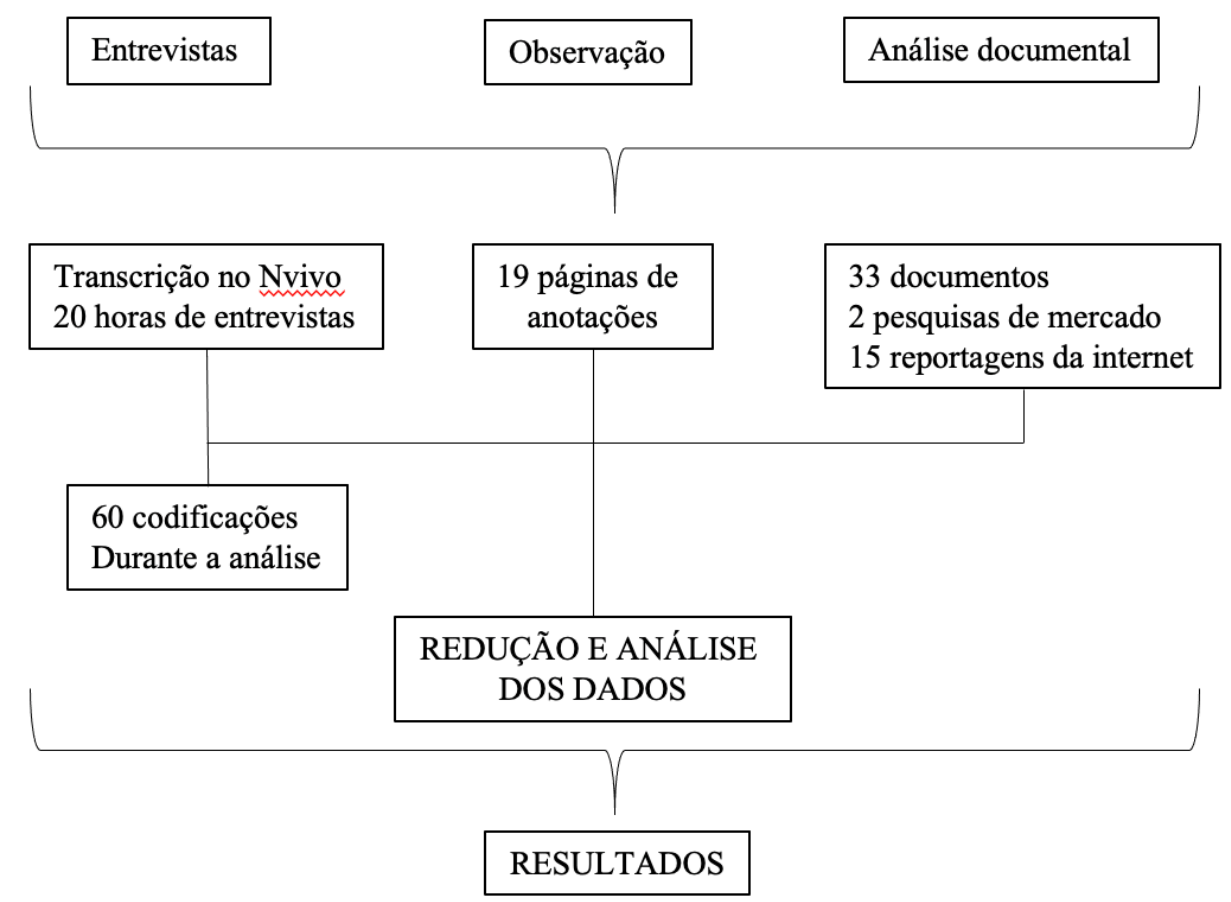

Figura 1. Resumo da coleta e análise dos dados

Fonte: Elaborado pelos autores

A codificação baseou-se em três códigos pré-definidos (definidos previamente na revisão da literatura): processo de desinstitucionalização, construção da sua legtimidade e maturidade do campo institucional. $\mathrm{Na}$ primeira fase foram identificadas mais de sessenta categorias durante a realização das entrevistas. E ao caminhar juntamente com a análise documental e observações realizadas foram realizadas várias comparações entre os discursos dos casos e os vários códigos eliminados, agregados ou adicionados, respeitando a abordagem inicial de conceitos já indicados pela literatura e adicionados aos conceitos emergentes.

Essa análise recursiva permitiu ampliar o aprofundamento dos dados, o que possibilitou emergir novas reflexões sobre o processo de desinstitucionalização da estrutura vigente nos polos, propondo reflexão, inclusive, sobre a forma como foi realizada a construção da legitimidade do empreendedor institucional e a influência do campo na construção dessa legitimidade, ao considerar os resultados da atuação dos empreendedores institucionais varejistas, sejam eles convocados ou espontâneos, mas presentes e atuantes no processo de revitalização. 


\title{
Resultados
}

Na seção seguinte, será apresentada a forma como a maturidade institucional dos polos varejistas de ruas influenciou na construção da legitimidade do empreendedor institucional varejista.

\section{A característica dos polos varejistas de ruas e sua influência na construção da legitimidade dos EIV's}

A partir da análise das entrevistas realizadas, percebeu-se que, mesmo a literatura abordando sobre a questão da maturidade o campo institucional, alguns elementos emergiram, sendo considerados cruciais na construção da legitimidade do empreendedor institucional durante o projeto de revitalização. Os elementos que emergiram foram: o baixo engajamento, a falta de orientação de mercado, ausência de senso de rede, além das questões culturais. A conjunção desses elementos permitiram a descoberta das características do campo pré-emergente que deriva da manutenção da estrutura vigente. Cabe ressaltar que tais características desse campo estão intimamente ligadas e se reforçam à medida que são combinadas, gerando barreiras na construção da legitimidade dos EIV's.

O surgimento desses princípios orientadores impediu o avanço da legitimidade do EIV's no seu campo de atuação. Identificou-se que a falta de engajamento dos varejistas dos polos (C1; C2; C3; C4; C5; C7; C8) impende a evolução concreta do projeto de revitalização, que se justifica com base em motivos comportamentais e culturais (C1; C2; C3; C7). Isso acaba por favorecer os varejistas dos polos, alertando para a não visualização dos benefícios que um projeto de revitalização pode gerar, como elevar a atratividade da rua e aumento das vendas, por exemplo, fatores esses verificados nos documentos dispobilizados pelos Sebrae. Porém, esses varejistas não estavam dispostos a investir em esforço adicional, por não vislumbrarem recompensas imediatas alinhadas aos seus interesses. Além disso, apresentaram como justificativas a falta de tempo, baixo interesse em participar das reuniões e problemas financeiros para contribuir com projeto.

\begin{abstract}
"Baixo, muito baixo (participação). Mas é aquilo que eu te falei, as pessoas vão, as pessoas gostam do projeto, [atual], legal, bacana, mas tipo: 'Agora eu não posso, eu tenho muita coisa para fazer, eu não consigo sair uma vez por semana para fazer reunião, eu não tenho quem deixar na loja, eu não tenho quem deixar no restaurante, eu não tenho quem deixa...', interesse até tem, só falta essa disponibilidade de entrega, porque na verdade é uma entrega e é o que a gente sempre fala, na verdade são empresários cuidando de uma associação, então todo mundo infelizmente vai ter que se doar um pouquinho em algum momento." (C3)
\end{abstract}

"Então foi... o processo de convencimento dos empresários, ele foi bem árduo assim, sabe? Realmente foi um desafio. Acho que esse foi o maior desafio, convencimento dos outros empresários, sabe? (C4)

Os varejistas dos polos não apresentaram um grau de presença física e emocional suficientes em relação às atividades do projeto de revitalização. O grau de engajamento dos varejistas e suas interações assumem um grau 
baixo de interação. Essa característica influenciou diretamente na construção da legitimidade, já que, para reverter este cenário os EIV's tiveram que desenvolver diversas estratégias de convencimento.

\begin{abstract}
"Mas no início, para começar a fazer um processo de revitalização desse, aparecia as vezes duas, três pessoas em uma reunião. Que era para aparecer trinta pessoas, aparecia três pessoas. Quer dizer, é de chorar. Tu te prepara para fazer um trabalho bom, se dedica, e aparece três, quatro, cinco. Dependendo da reunião, tinha quóruns assim, bastante inexpressivos, bastante baixa a presença. Mas existia uma vontade muito grande de fazer, e que a gente via que valia a pena investir." (C4)

Eu te dou um doce se você conseguir envolver empresários, porque eles não querem. É essa a fala. Não, o que você está falando é bonito, mas não consegue, porque a gente não conseguiu. Então foi um trabalho de quase dois anos de, realmente, ir lá, conversa com empresário, vai, conversa com outro, começa a mostrar o que que é possível (C7)
\end{abstract}

Frente ao exposto, observou-se uma falta de conectividade entre a prática de gestão e a visibilidade futura de negócio, ou seja, orientação para o mercado (C1;C4;C5;C6;C7;C8). Geralmente, espera-se que varejistas procurem soluções para resolver seus problemas de negócio, tendo como ênfase os consumidores e as suas reais necessidades. Essa falta de orientação para a sobrevivência de mercado influencia diretamente o desempenho do polo de rua, como de fato ocorreu com o surgimento de shopping centers (C1;C4;C5;C6;C7;C8) e novas formas de canais de compra (C1;C5;C7). A preocupação em relação aos concorrentes foi verificada também na pesquisa disponiblizada pelo Sebrae local. O resultado da pesquisa mostrou que 65\% dos empresários varejistas da rua consideraram o avanço dos concorrentes como a maior dificuldade na gestão dos negócios.

Nesse contexto analisado, notou-se que os varejistas não apresentaram uma capacidade de resposta efetiva e coordenada para acompanhar as tendências mercadológicas, como o processo de declínio da rua, cujo papel do EIV's foi tentar reverter esse processo. A observação realizada no caso C1 evidenciou, por exemplo, problemas críticos na infraestrutura, como calçadas quebradas, lixo espalhado na calçada, falta de sinalização e orientação para consumidor. Esse processo gerou fuga dos consumidores para novos canais de compras (C1).

"[...] com a ascensão do e-commerce, o shopping chegou, então foi toda uma situação, se o comércio local parar, estagnar, vai morrer, ninguém vai sair de casa para comprar, vai comprar pela internet ou vai no shopping comprar, se precisar de algo de pronta entrega. Se eles não fizerem algo diferente o comércio vai morrer." (C6)

"[...] mas por parte dos empresários eu vejo isso mesmo, falta essa visão, alguém que tenha uma visão um pouquinho mais visionária de futuro, falar: 'pô, esse projeto é uma boa, Sebrae, Fecomércio, a prefeitura, estão investindo, estão botando dinheiro para nos ajudar', isso é coisa que nem precisava acontecer, porque o setor privado, por si só, tinha que caminhar. Eles poderiam se organizar e fazer o negócio funcionar e melhorar a rua, só que eles não fazem". (C8)

Processos de orientação de mercado, praticados nos polos, precisam de esforços coletivos e coordenados para que seja possível permitir a criação de uma estrutura robusta e que resulte em percepções positivas ao 
consumidor, variáveis não encontradas pelos EIV's neste formato de campo pré-emergente $(\mathrm{C} 1 ; \mathrm{C} 2 ; \mathrm{C} 3 ; \mathrm{C} 4 ; \mathrm{C} 5 ; \mathrm{C} 6 ; \mathrm{C} 7 ; \mathrm{C} 8)$. No entanto, cabe ressaltar que os documentos analisados demostraram que empresários varejistas tinham consciência dos benefícios em relação ao projeto de revitalização. Acreditavam que o projeto melhoraria o comércio da rua ficando mais atrativa e principalmente e que aumentaria as vendas com o aumento do fluxo de consumidores. Essa visão não foi compartilhada durante a execução do projeto de revitalização pelo EIV's.

"Ninguém queria... todo mundo apoiava, mas ninguém tinha tempo pra se envolver. Estava todo mundo preocupado só com o seu. O que é muito da cultura brasileira, não é? Se fala em coletivo, eles apoiam, eles: nossa, legal, não sei o quê. Mas então agora, resolve. Então vamos, vamos, me dá o contato aí, vamos lá. Então eu falei: gente, eu não vou ficar esperando. Então fui atrás mesmo, e fui sozinha." (C2)

"É como eu te disse, é o perfil mais egoísta, ele via o vizinho como um concorrente, por mais que estejam ali há anos, ele via como concorrente, então cada um queria ser maior que o outro, eles não tinham a percepção de que eles juntos, eles iam ganhar mais." (C6)

A falta de visão de coletivo implicou acionar princípios que apenas reduziram a legitimidade do EIV's, não permitindo a conectividade de relações entre os varejistas, EIV's e demais instituições externas ao campo. Além disso, um dos fatores que reforçaram ainda mais as características do campo pré-emergente foram alguns aspectos culturais (C1;C3;C6; C7;C8), como idade dos varejistas dos polos, modelo de negócio ultrapassado ou transferência de responsabilidade:

"É, tinha uns novos e tinha alguns antigos também, bem antigos. Tinha, eu diria para você que os mais antigos eram os piores. Eram os mais difíceis é." (C1)

"[...] O comércio da Riachuelo é feito por pessoas muito antigas de seus comércios, eu acredito que é até um pouco desse processo vai muito talvez pela idade dos seus donos, sei lá, tem pessoas que são muito fechadas, até pela próprio cultura dele, 'Ah imagina se eu vou me a...' muitos já estão frustrados, a gente ouviu muito isso, de associações que eles entraram e que não deu certo, que começou e não terminou, sempre tem essas histórias, ai quem é novo também não está muito interessado, quando eu falo novo, é jovem que está começando agora, eu acho que quando a gente, por incrível que pareça, o que eu vejo são mais envolvidos com cultura digamos assim, não cultura educacional, mas cultura mesmo, de shows, quem mexe nessa área, se envolve muito mais, parece que tem um olhar mais romântico, mas sonhador [...]" (C3)

O somatório dessas características apresentadas permitiu gerar as categorias deste campo pré-emergente, conforme demostra o Quadro 3, que interferiu diretamente na construção da legitimidade do EIV's. 
Quadro 3: A construção da legitimidade do EIV's

\begin{tabular}{|c|c|c|c|c|}
\hline Categoria & Subcategoria & Descrição & $\begin{array}{c}\text { Impacto } \\
\text { no Campo } \\
\text { Institucional }\end{array}$ & $\begin{array}{l}\text { Influência na } \\
\text { legitimidade do EIV }\end{array}$ \\
\hline \multirow{4}{*}{$\begin{array}{c}\text { Campo } \\
\text { Pré-Emergente }\end{array}$} & Baixo engajamento & $\begin{array}{c}0 \text { envolvimento dos atores como facilitadores } \\
\text { para criar, construir e apoiar projetos institucionais } \\
\text { é visto como interessante, mas não apresenta } \\
\text { comportamentos para sustentar uma vantagem } \\
\text { competitiva para desenvolvimento do campo } \\
\text { institucional } \\
\end{array}$ & \multirow{4}{*}{$\begin{array}{l}\text { Manutenção da } \\
\text { estrutura vigente }\end{array}$} & \multirow{4}{*}{$\begin{array}{l}\text { Barreiras que interferem } \\
\text { na construção da } \\
\text { legitimidade e como } \\
\text { consequência influência } \\
\text { na atuação do El } \\
\text { no desenvolvimento } \\
\text { de novas estruturas } \\
\text { institucionais }\end{array}$} \\
\hline & $\begin{array}{l}\text { Falta de orientação } \\
\text { para mercado }\end{array}$ & $\begin{array}{l}\text { Atores no campo possuem consciência das } \\
\text { interferências ambientais e mercadológicas mas } \\
\text { não realizam um monitoramento contínuo das } \\
\text { necessidades atuais e latentes dos clientes e as } \\
\text { condições de mercado e concorrência, assumindo } \\
\text { posições de inércia e evitando o processo de } \\
\text { inovação, de desenvolvimento de estratégias } \\
\text { alinhadas com as expectativas dos consumidores } \\
\text { para reverter o processo de declínio ou elevar a } \\
\text { atratividade do campo }\end{array}$ & & \\
\hline & $\begin{array}{l}\text { Falta de senso de } \\
\text { rede }\end{array}$ & $\begin{array}{c}\text { Senso de rede permite criar novas formas e } \\
\text { estruturas organizacionais por meio de padrões } \\
\text { de relações, ao vincularem os atores em torno de } \\
\text { objetivo comum. }\end{array}$ & & \\
\hline & Cultura & $\begin{array}{l}\text { Padrões comportamentais compartilhados entre } \\
\text { um grupo que suportam a estrutura institucional }\end{array}$ & & \\
\hline
\end{tabular}

Fonte: Elaborado pelos autores

Mesmo com o desenvolvimento de estratégias para alavancar a sua legitimidade, os EIV's encontraram dificuldades para mobilizar, articular e convencer os demais varejistas, no intuito de atuarem em conjunto no projeto de revitalização, em decorrência do baixo engajamento, falta de orientação de mercado, falta de senso de rede e questões culturais. A combinação desses elementos não permitiu a sustentação da legitimidade do EIV's durante o processo de revitalização. Para reverter a situação e desinstitucionalizar as práticas vigentes entre os varejistas, diversas ações foram realizadas pelos EIV's, com objetivo de sensibilizar e mobilizar os varejistas do polo.

Primeiramente foram realizadas visitas técnicas em outros polos varejistas que percorreram os processos de revitalização com o intuito de verificarem, na prática, os benefícios resultantes do projeto. Reuniões foram realizadas para apresentar mais detalhes dos projetos, além de designações de lideranças por quadras, para ampliar as estratégias de convencimento com apresentação de materiais específicos sobre o projeto, com visitas door-to-door para aumentar o convencimento em cascata. No entanto, a participação permaneceu baixa. Em segundo lugar, os EIV's buscaram empréstimos de legitimidade por meio de parcerias externas aos polos, com o objetivo de elevar o engajamento dos varejistas e ampliar o senso de rede. 
Isso foi verificado na análise documental, a qual evidenciou a relevância dos jornais e da internet no processo de divulgação do projeto de revitalização e participação do poder público com visitas in loco. Isso foi verificado nas reportagens coletadas da internet que apreentaram a participação dos(as) prefeitos(as) ou no início ou na entrega das obras.

\begin{abstract}
A cerimônia de entrega das obras contará com a presença da prefeita (nome da prefeita), que bancou $R \$ 1,3$ milhão do projeto. $A$ associação comercial arcou com $R \$ 16 \%$ das despesas da reforma ( $R \$ 330$ mil). O trânsito estará interditado na rua das $6 \mathrm{~h}$ até as $21 \mathrm{~h}$ para que ela seja transformada em um palco para espetáculos artísticos. (C1)

O prefeito (nome do prefeito) entrega hoje, às 10h, as obras de revitalização da Rua Riachuelo. "Com este projeto, a Riachuelo recupera sua importância e ganha novo ânimo que movimentará o comércio e trará mais segurança aos moradores" (C4)
\end{abstract}

Em terceiro lugar verificou-se também que apenas dois polos (C1; C2) conseguiram avançar no processo de institucionalização, pela criação de associações dos varejistas do polo. Tal estratégia permitiu elevar o grau de institucionalização desses polos, mesmo que minimamente. Após apresentarem características de pessoa jurídica, esses polos ampliaram o seu acesso a outras instituições, tais como: poder público, outras Associações Comerciais, Sebrae e Redes de Comunicação. Apenas em C2, a EIV desenvolveu de fato um modelo de negócio para Associação Comercial da Rua de maneira sustentável, com formas de captação de varejistas, materiais institucionais, equipe própria, estratégias mercadológicas entre as lojas, desenvolvimento de eventos, comunicação constante com varejistas e atividade remunerada.

Em C1, os EIV's até desenvolveram uma associação inicialmente forte e permaneceu ativa durante muitos anos. No decorrer do tempo e pela força do campo e desvio de interesses dos EIV's, a associação foi desativada e a tendência da rua está para declínio, baseando-se nas observações e notas de campo coletadas nesse polo de rua. Além disso, cabe ressaltar que os melhores resultados foram apresentados pelos empreendedores institucionais que surgiram de forma espontânea (C1; C2). Outro fator crítico é que EIV's dos demais polos ainda encontram dificuldade para profissionalizar as suas instituições, devido ao elevado grau de dependência financeira dos varejistas, baseado em mensalidade e disponibilidade de tempo para gerir suas próprias lojas. Nesse contexto, detectou-se a existência de uma divisão, com escassez de tempo e recursos, o que impediu a sustentabilidade dessas instituições internas no polo. No entanto, para lidar com o desafio de manutenção dessas instituições, os EIV's ainda encontram resistência dos atores varejistas, devido ao seu perfil de baixo engajamento e falta de orientação de mercado e ausência de senso de rede (C1;C3;C5;C7). Mesmo apresentando resultados concretos, os varejistas do polo não assumem uma posição colaborativa.

Portanto, o polo varejista exigiu um elevado grau de esforço destes empreendedores no intuito de desinstitucionalizar práticas vigentes apresentadas de forma não ordenada, com institucionalização em fase embrionária, sendo reforçada pela ausência de orientação de mercado, engajamento, senso de rede e questões culturais. O esforço dos EIV's tinha como objetivo a tentativa de avançar na agenda de mudança proposta 
pelo projeto de revitalização, cujo propósito era obter resultados coletivos e de acordo com a reversão do declínio dos polos varejistas. No entanto, observamos que o campo institucional pré-emergente do polo varejista não permitia a atuação na íntegra dos EIV's, forçando a manutenção da estrutura vigente e prejudicando a construção da sua legitimidade.

\section{Principais resultados alcançados pelos EIV's no projeto de revitalização, após a construção da sua legitimidade do polo varejista}

O projeto de revitalização foi fruto de uma visão do processo de declínio das ruas e da necessidade de reverter esse cenário. Nesse entremeio, mesmo sendo convocados na sua grande maioria e destinados a atuarem como EIV's, esses atores encontraram diversas barreiras no processo de desinstitucionalização da estrutura vigente dos polos de ruas, cujo propósito tinha como foco a construção da sua legitimidade visando avançar no projeto. Mesmo com as características do campo pré-emergente influenciando na legitimidade dos EIV's, foi possível atingir resultados concretos no projeto de revitalização, mas, em alguns casos, foram interrompidos, não ultrapassando a idealização do projeto. Observou-se uma forte concentração do varejo no campo pré-emergente $(\mathrm{C} 4 ; \mathrm{C} 5 ; \mathrm{C} 6 ; \mathrm{C} 7 ; \mathrm{C} 8)$ de forma a influenciar a construção da legitimidade do empreendedor institucional varejista, gerando impacto direto nos resultados do projeto.

Nos casos C6 e C8, os EIV's encontraram um grau de dificuldade elevado ao estabelecer uma relação com as autoridades políticas locais voltadas a endossar o projeto de revitalização. A falta de transparência e compromisso público descontruíram e fragilizaram a legitimidade desses EIV's com os seus pares varejistas, o que fez emergir uma crise de desconfiança e credibilidade, impedindo o avanço do projeto. A participação do setor público é núcleo do processo de revitalização, haja vista a apresentação de um estoque de legitimidade elevado no campo, devido às suas características reguladoras. Quando o setor público endossa o projeto, em paralelo, o EIV's eleva a sua legitimidade no polo varejista, facilitando a articulação (C1; C2; C3; C4; C7), o que resulta em os resultados mais efetivos.

Os EIV's que conseguiram percorrer a etapa da revitalização apresentaram resultados comuns e que trazem à tona o aumento da segurança, adequação da infraestrutura, atração de novos varejistas, maior visibilidade na mídia, referência para outros polos varejistas, retorno dos consumidores e valorização imobiliária. Além disso, após a revitalização, as vendas aumentaram consideravelmente $(\mathrm{C} 1 ; \mathrm{C} 3 ; \mathrm{C} 4 ; \mathrm{C} 5)$. No caso $\mathrm{C} 1$, por exemplo, varejistas perceberam um aumento de $20 \%$ a $30 \%$ nas vendas. Cabe ressaltar também a relevância da perenidade das associações criadas com o intuito de representar as ruas. EIV's atuam em projetos para garantir a sua continuidade no desenvolvimento de estratégias mercadológicas para a rua, como ações promocionais ou fóruns de discussões dos novos problemas que emergem nesse contexto. Isso também contribuiu para aumentar a atratividade, retorno dos consumidores e elevação do faturamento. 


\section{Influência do polo varejista na desconstrução da legitimidade do EIV's}

Após conseguirem estabelecer os resultados do processo da revitalização, alguns EIV's tentaram manter a atuação no polo varejista com propósito de defender os interesses coletivos dos atores destes polos em epígrafe. (C1; $\mathrm{C} 2$; $\mathrm{C} 3$; $\mathrm{C} 5$; $\mathrm{C} 7$; $\mathrm{C} 8)$. No entanto, a tipologia do campo pré-emergente influenciou o EIV's, gerando desconstrução da sua legitimidade. Tem-se em mente que os EIV's atuam na rua, possuem as suas respectivas lojas e agem nesse projeto de revitalização como voluntários convocados ou são ainda espontâneos. Apesar dessa vontade de atuar como EIV's, os varejistas não recebem remuneração para conduzir tais projetos ou para realizarem a gestão de Instituições criadas para representar a rua. Isso eleva a demanda de atividades e conflitos de interesses entre o atuar como EIV e posicionar-se como varejista:

"Não, porque acima de tudo, a minha vida profissional e pessoal está acima de qualquer coisa. O que acontecia é que eu tinha uma sobrecarga de trabalho. Então se eu tivesse que fazer algum trabalho, nem que fosse em horário extraordinário, eu faria, mas para não atrapalhar a minha atividade profissional. Porque eu não ia fazer uma atividade sem fim lucrativo nenhum, prejudicar o meu dia a dia e o meu ganha pão." (C1)

"É uma coisa que eu não consigo entender até hoje. Eu fico revoltado, você visita os vizinhos, a gente, por exemplo, o nosso trabalho aqui é um trabalho voluntário, a gente não ganha nada para participar do projeto, a gente perde tempo, larga o nosso negócio, às vezes, aqui onde eu trabalho, eu largo o meu restaurante e vou atrás de coisa." (C7)

Como os varejistas dos polos não respondem e não promovem diálogo coeso no intuito de melhorar a atratividade local, EIV's desistem da proposta e seguem rumo aos novos projetos e oportunidades pessoais, finalizando o projeto, mas não possuindo sucessores para a manutenção da proposta:

"[...] o maior desvio que eu vejo é político. Eu mesmo já tive um período que eu falava assim, nossa, puxa vida, se eu me candidatasse seria um... poderia ser, porque a pessoa fica pensando, às vezes, dá muita mídia, e tal, em cidades menores ele fica até meio que enfeitiçado, mas aí ele perdeu o foco." (C1)

Ela consegue trazer alguns empresários. Mas talvez também fosse o momento de renovação de liderança. Só que ao mesmo tempo, não tem alguém que tenha essa mesma pegada que ela, entendeu?" (C4)

Além disso, o próprio polo varejista pode gerar um isolamento do EIV referente à agenda de mudança institucional e este perde a sua legitimidade no campo institucional, não conseguindo mais ter acesso às organizações externas ao polo, já que a sua legitimidade foi descontruída:

\footnotetext{
"Aí uma série de... começou a convergir fatores negativos, você fala assim, "bom, é melhor eu ficar tocando só a minha loja, porque aqui eu não estou vendo para onde possa correr." (C1)

“'Ah, mas é a prefeitura?'. Pô, não consigo marcar nenhuma reunião com o subprefeito. Antes eu ligava num dia, no dia seguinte estava no gabinete da Martha. Não é possível. Não conseguia. Então eu comecei a encontrar dificuldade em tudo quanto é canto" (C1)
} 
Esses ingredientes são críticos e fragmentam a legitimidade dos EIV's e seu propósito. Observamos que as características do campo pré-emergente, além de dificultar a construção da legitimidade do EIV, geram a fragmentação da nova proposta institucional rubricada pelos EIV's e potencializada de acordo com o desvio dos seus propósito, conforme quadro 4.

Quadro 4: A desconstrução da legitimidade do EIV's

\begin{tabular}{|c|c|c|c|c|c|}
\hline Dimensão & Categoria & Subcategoria & Descrição & $\begin{array}{c}\text { Impacto } \\
\text { para Campo } \\
\text { Institucional }\end{array}$ & $\begin{array}{c}\text { Influência na } \\
\text { legitimidade do } \\
\text { EIV }\end{array}$ \\
\hline \multirow{6}{*}{$\begin{array}{l}\text { Influência do } \\
\text { campo }\end{array}$} & \multirow{6}{*}{$\begin{array}{l}\text { Perda de } \\
\text { legitimidade }\end{array}$} & $\begin{array}{l}\text { Conflito de } \\
\text { interesses }\end{array}$ & $\begin{array}{l}\text { Conjugação entre projeto institucional } \\
\text { e manutenção da sua própria estrutura }\end{array}$ & \multirow{6}{*}{$\begin{array}{l}\text { Atores do campo } \\
\text { geram fragmentação } \\
\text { da nova proposta } \\
\text { institucional e } \\
\text { potencializam o } \\
\text { desvio do propósito } \\
\text { do EIV }\end{array}$} & \multirow{6}{*}{$\begin{array}{l}\text { Desconstrução da } \\
\text { legitimidade do } \\
\text { EIV sendo forçado } \\
\text { a retornar seu } \\
\text { posicionamento } \\
\text { inicial no campo } \\
\text { institucional onde } \\
\text { atua. }\end{array}$} \\
\hline & & Voluntarismo & $\begin{array}{l}\text { Atuação do EIV sem fins lucrativos } \\
\text { e com elevada dependência de } \\
\text { contribuições dos atores do campo } \\
\text { para gerar recursos e manter a } \\
\text { proposta institucional }\end{array}$ & & \\
\hline & & $\begin{array}{l}\text { Falta de } \\
\text { sucessão }\end{array}$ & $\begin{array}{l}\text { Falta de sucessão e criação de } \\
\text { novas lideranças para criação ou } \\
\text { manutenção de novas propostas } \\
\text { institucionais. }\end{array}$ & & \\
\hline & & Isolamento & $\begin{array}{l}\text { Perda de apoio dos atores do campo e } \\
\text { de aliados gerando isolamento do EIV. }\end{array}$ & & \\
\hline & & $\begin{array}{l}\text { Fuga para novos } \\
\text { projetos }\end{array}$ & $\begin{array}{l}\text { Desenvolvimento de novos projetos } \\
\text { com ganhos financeiros para EIV }\end{array}$ & & \\
\hline & & $\begin{array}{l}\text { Demanda } \\
\text { elevada }\end{array}$ & $\begin{array}{l}\text { Excesso de responsabilidades para } \\
\text { construção do projeto institucional } \\
\text { para o campo vigente }\end{array}$ & & \\
\hline
\end{tabular}

Fonte: Elaboração própria baseada na codificação dos dados.

Esse cenário acaba por contribuir para a desconstrução da legitimidade dos EIV's, que são forçados a retornar a sua posição inicial no campo institucional. O resultado é que nenhum varejista é beneficiado nesse escopo, além de enfraquecer a sua própria estrutura e fortalecer a desinstitucionalização do polo de rua no campo, ou seja, o seu declínio.

\section{Discussão dos resultados}

Esta pesquisa foi construída a partir da atuação dos empreendedores institucionais varejistas em projetos de revitalização de oito polos varejistas. Os resultados indicam uma forte influência do grau de institucionalização na construção da legitimidade do empreendedor institucional varejista. Os EIV's e os polos varejistas estavam posicionados no campo organizacional, os polos varejistas de ruas, denominados nessa pesquisa como campo pré-emergente, em complemento à tipologia proposta pela literatura (Battilana et al., 2009; DiMaggio \& Powel, 1983; Fligstein \& Mara-Drita, 1996; Fligstein \& McAdam, 2011; Greenwood et al., 2002; Greenwood \& Suddaby, 2006; 
Hoffman, 1999; Holm, 1995; Maguire et al., 2004), como se pode ver no Quadro 5.

Nota-se que o campo pré-emergente estava enraizado no baixo engajamento, baixa orientação de mercado, falta de senso de coletividade e atores agindo de forma situacional, alinhados aos benefícios de seus interesses. Essas características são consideradas menos propensas à construção da legitimidade do EIV's, além de reforçar o baixo grau de institucionalização dos polos varejistas de rua. A pesquisa sugere que os EIV's sofreram forte influência da baixa institucionalização dos polos varejistas de rua e estes usaram diversas estratégias, a fim de construir a sua legitimidade na tentativa de elevar o grau de institucionalização da rua e gerar condições mínimas para conduzirem o projeto. Ou seja, mesmo com objetivo claro e direcionado a criar novas formas institucionais (Battilana et al., 2009; Garud et al., 2007), além de promover mudanças (Suddaby \& Greenwood, 2005), os empreendedores varejistas não conseguiram romper as barreiras impostas pelo campo pré-emergente. Barreiras estas que podem ser justificadas pela falta de consciência dos varejistas ao desconsiderarem a possibilidade de estruturarem-se como instituição. Vê-se, nesse contexto, que o compartilhamento dos esquemas do campo gerou comportamentos padronizados (Scott, 2008) pelos atores varejistas alocados nos oitos polos de ruas e que, com isso, acabaram por assumir uma posição dominante, cuja proposta é manter o status quo do campo (Fligstein, 1997).

Os empreendedores institucionais varejistas acreditavam que, pelo cenário de declínio do polo, a descontinuidade dessas práticas do campo pré-emergente poderiam ser rompidas com o projeto de revitalização. Tentaram desinstitucionalizar essas práticas, a fim de propiciar a abertura para adoção de uma nova legitimidade institucional (Aldrich \& Fiol, 1994; Dacin et al., 2002a). Nesse ínterim, o projeto de revitalização apresentava uma proposta coerente, no intuito de elevar a atratividade local e promover o seu desenvolvimento (Dokmeci et al., 2007; Milchen, 2005; Presti, 2003) e atrair novos consumidores (Hart et al., 2013; Kupke \& Valerie, 2004; Pryor \& Grossbart, 2005).

Quadro 5: Tipologia dos campos institucionais

\begin{tabular}{|c|c|c|c|}
\hline Pré-emergente & Emergente & Maduro & Declínio \\
\hline $\begin{array}{l}\text { As práticas são fundamentadas no } \\
\text { baixo engajamento, falta de senso de } \\
\text { rede e orientação mercadológicas. } \\
\text { Fortalecendo a inexistência da } \\
\text { institucionalização. } \\
\text { Tais características são reforçadas } \\
\text { pelas questões culturais praticadas } \\
\text { pelo campo, como a busca da } \\
\text { defesa de interesses individuais e } \\
\text { imediatista. } \\
\text { Iniciativas de institucionalização } \\
\text { sofrem riscos de descontinuidade } \\
\text { imediata. }\end{array}$ & $\begin{array}{l}\text { Apresenta algum grau de } \\
\text { interesse mútuo. } \\
\text { Existe relativamente } \\
\text { pouca ação coordenada } \\
\text { entre eles }\end{array}$ & $\begin{array}{l}\text { As interações e rotinas já } \\
\text { são estabelecidas entre os } \\
\text { participantes que possuem } \\
\text { forte consciência de suas } \\
\text { posições no campo. } \\
\text { As relações de poder e as } \\
\text { coalizões são definidas com } \\
\text { objetivo comum }\end{array}$ & $\begin{array}{c}\text { Gerados pela convivência } \\
\text { social, a ruptura tecnológica, a } \\
\text { descontinuidade competitiva e as } \\
\text { mudanças regulatórias que podem } \\
\text { perturbar o consenso construído } \\
\text { socialmente no terreno. } \\
\text { Os atores dominantes em uma arena } \\
\text { começam a falhar, seja por invasão } \\
\text { por grupos de outros campos, } \\
\text { fracasso organizacional dentro do } \\
\text { campo ou fatores exógenos }\end{array}$ \\
\hline
\end{tabular}

Fonte: Elaboração própria baseado na codificação dos dados 
A análise documental reforça que os varejistas estavam preocupados com a concorência e apoiavam o projeto. Isso seria uma abertura para atuação do El quando os atores estão em não-conformidade com as instituições que supostamente governam seu comportamento (Hardy \& Maguire, 2008; Seo \& Creed, 2002), por exemplo, o setor público.

Neste contexto, o polo varejista apresentava-se de forma desorganizada e fragilizada, e o projeto de revitalização reforçava as falhas existentes, cujos seus resultados seriam superiores à estrutura vigente, corroborando com a ideia de unir os atores e reduzir as contradições no campo (Boxenbaum \& Battilana, 2005; Fligstein, 1997; Holm, 1995; Seo \& Creed, 2002; Suddaby \& Greenwood, 2005). E mesmo com promessa de sucesso e evidenciando vantagens significativa (Garud et al., 2002), os varejistas dos polos assumiram passiva e críticos em relação projeto. Diante do exposto, averigou-se que, quando campo insitucional não apresetnar grau mínimo de institucionalização e o empreendedor não possui um estoque mínimo de legitimidade, será questionado de forma constante (Déjean et al., 2004) .Essa configuração dificultou o acesso dos empreendedores a recursos e na capacidade de unificar diversos atores varejistas (Aldrich \& Fiol, 1994; Battilana et al., 2009; Zelditch, 2001).

Nesta abordagem de baixa institucionalização do campo, cabe ressaltar dois pontos relevantes e encontrados no campo de pesquisa. O primeiro deles corresponde à forma como surgiram os empreendedores institucionais e o segundo, evidencia a forma como cada perfil atuou nesta configuração do campo pré-emergente. A combinação desses dois pontos interferiu diretamente na entrega dos empreendedores institucionais. Nos casos de empreendedores que surgiram espontaneamente $(\mathrm{C} 1 ; \mathrm{C} 2)$, acabaram por assumir comportamentos de empreendedores institucionais (Battilana et al., 2009; Boxenbaum, 2004; Greenwood \& Suddaby, 2006), emergindo uma inquietação no que tange à estrutura em declínio (C1), ou pela necessidade de elevar ainda mais a atratividade do polo (C2). Nesse entremeio, construíram o projeto de revitalização de forma independente, financiando os custos entre os seus pares e, posteriormente, buscaram fontes de financiamento com empresas privadas. Além disso, conseguiram criar associações para elevar a sua legitimidade no campo e, como resultado, conseguiram acesso e apoio do setor público.

Os empreendedores convocados surgem pela convocação de instituições externas ao polo e com elevado grau de legitimidade no campo institucional, tais como o Sebrae, as Associações Comerciais e a Rede de televisão. A inquietação do declínio dos polos emerge destas instituições e não propriamente dos varejistas. Além disso, a escolha dos varejistas para atuarem no projeto é realizada pelas escolhas destas instituições e que possuíam como objetivo estabelecer essa relação com polo, sendo o empreendedor convocado a assumir a condição de facilitador no projeto de revitalização. Mesmo sendo endossados por instituições (David et al., 2013), isso não significa que estes empreendedores apresentavam perfil ou possuíam legitimidade suficiente para atuarem no polo varejista.

Ao analisar os resultados finais do projeto de revitalização, os casos em que empreendedores institucionais surgiram, de forma espontânea, obtiveram mais sucesso quando comparados aos espontâneos. Isso vem 
reforçar que empreendedores institucionais precisam realmente apresentar alguns elementos, dentre eles a capacidade de transpor lógicas dominantes (Boxenbaum \& Battilana, 2005) e criar processos de cooperação para produzir novas lógicas insitucionais (Garud et al., 2002; Lawrence et al., 2002) por meio da sua legitimidade (Dacin et al., 2002b; Meyer \& Rowan, 1977; Scott, 1987; Zucker, 1987). Apensar das diferenças, ambos convocados e espontâneos encontraram as mesmas dificuldades e, em alguns casos, utilizaram estratégias similares para avançarem no projeto.

Os EIV's tentaram elevar a sua legitimidade utilizando o setor público, criando ligação permissiva, que com externalização das suas características de regulação, autoridade e legislação foi possível elevar o grau de legitimidade dos EIV's. Vinculando-se, por exemplo, com a prefeitura ou Sebrae, o El busca sair em busca de legitimidade externa com uma autoridade formal intencionada a validar o seu discurso de mudança (Fligstein, 1997; Maguire et al., 2004; Phillips et al., 2000). Essa estratégia, desenvolvida pelo El, reforça necessidade de unir-se com outros atores legítimos para que possam emprestar a legitimidade (David et al., 2013). Com a aprovação e apoio do setor público, os EIV's conseguiram avançar na construção da sua legitimidade para poder atuar de forma significativa na revitalização. Mediante o envolvimento do setor público, os varejistas dos polos compreenderam as intenções do projeto de revitalização, permitindo o início da pré-institucionalização dos polos, ampliando, mesmo que minimamente, o engajamento deles no projeto. Essa parceria permitiu maior visibilidade ao projeto nos meios de comunicação e esse resultado foi utilizado pelos EIV's como estratégia de mobilização e convencimento perante os demais varejistas para aumentar o engajamento no projeto de revitalização.

No entanto, isso não significa que a legitimidade dos EIV's rompeu a estrutura do campo pré-emergente por meio dessa ligação permissiva. Se por um lado o poder público assumiu um papel central no processo de revitalização, por outro, provocou a ineficiência no trabalho de gestão pública, potencializando a resistência dos varejistas e reduzindo a legitimidade dos EIV's. Em todos os casos analisados, as Prefeituras apresentaram problemas nas etapas do projeto de revitalização, desde escassez de recursos financeiros, conflito de interesses entre varejistas e até mesmo o partido vigente na Prefeitura, o qual ensejou um clima de desconfiança na manutenção da parceria com a rua. Além disso, houve baixa mobilização pública e desenvolvimento de estratégias de convencimento em relação à relevância do projeto com atrasos no cronograma das obras e manutenção da rua que, mesmo após revitalização, pôde contribuir negativamente na construção da legitimidade dos EIV's. Esse contexto potencializou os questionamentos dos varejistas em relação ao EIV's, prejudicando a sua legtimidade durante a excução do projeto (Déjean et al., 2004).

Mesmo recorrendo ao endosso de instituições externas visando construir a sua legitimidade, também não foram reconhecidas e validadas, apenas estavam em concordância com os varejistas de rua. Isso reforça o posicionamento da maturidade, presente no campo institucional, capaz de influenciar diretamente na legitimidade do El (Fligstein, 1997; Greenwood \& Suddaby, 2006; Maguire et al., 2004), ressaltando que devem existir condições mínimas para garantir a sua atuação. Conclui-se, portanto, que 
esta pesquisa contribuiu e ampliou a discussão ao apresentar quais fatores podem gerar essa inferência direta na construção da legitimidade do El, pouco explorada pela literatura até então, além de demonstrar como o campo pode contribuir para a perda da legitimidade.

Logo após a criação das mínimas condições de atuação, os EIV's observaram o descompasso entre as suas ações e as respostas dos seus pares varejistas. Nesse interim, os lojistas apresentavam baixo engajamento, baixo senso de coletividade e, como consequência, potencializavam a vulnerabilidade do polo, devido à falta de orientação mercadológica. Esse conjunto de fatores enfraqueceu o processo de construção da legitimidade do EIV's e, em alguns casos, a estrutura mínima construída por eles visa romper o campo pré-emergente, que foi desconstruído. Em alguns polos, ou existiu a desativação das instituições da rua devido à falta de contribuição e interesse, ou os varejistas estavam direcionados a agirem de maneira situacional, em benefícios de seus interesses individuais, aproveitando-se das ações do EIV's para se beneficiarem, mas sem o propósito de engajar nos projetos propostos pelos EIV's de forma coletiva, impactando na construção da legitimidade. Ou seja, mesmo quando foi proposta uma agenda de mudança, estratégias de convencimento e mobilização (Boxenbaum \& Battilana, 2005; Holm, 1995; Seo \& Creed, 2002) de forma a construir alternativas melhores (Leca et al., 2008; Seo \& Creed, 2002) com capacidade de alinhar soluções e interesses coletivos (Snow \& Benford, 1992 apud Rao, Morrill, \& Zald, 2000), os EIV's não conseguiram romper a estrutura do campo pré-emergente, a ponto de criarem condições mínimas de legitimidade e elevar o grau de institucionalização dos polos varejistas.

Conforme sugerido, dependendo da estrutura do campo e das características dos atores, os empreendedores institucionais podem não conseguir romper a estrutura vigente e, feito isso, podem propor uma agenda voltada à formatação de uma nova estrutura, em decorrência da falta de legitimidade. Desta forma, a atuação dos empreendedores institucionais no campo pré-emergente pode não garantir que a sua visão inovadora seja aceita, desenvolvida ou continuada, pois o campo pré-emergente necessita apresentar, no mínimo, um grau de engajamento, orientação para mercado e senso de rede focado na atuação do empreendedor institucional, caso contrário, a sua construção de legitimidade e seus esforços na busca de novas estruturas poderão ser pontuais e sem continuidade.

\section{Conclusões}

Nesta pesquisa discutiu-se os resultados sobre como o grau de matruidade insitucional do polo varejista pode influenciar na construção da legitimidade do empreendedor institucional varejista. A exploração dessa questão, conduzida no contexto de revitalização das ruas varejistas, sugere que é crucial considerar a tipologia do campo institucional antes do empreendedor insitucional iniciar suas atividades. Observamos que as práticas do campo varejista estavam fundamentadas no baixo engajamento, falta de senso de rede e orientação de mercado. Tais características parecem ser reflexos de características culturais existentes no campo, como o pouco 
espírito de trabalho cooperativo em grupo, uma visão de curtíssimo prazo e de interesses individuais. Esses fatores nos permitiram identificar a existência de um campo pré-emergente, tornando-se uma nova contribuição para criar um quarto tipo na tipologia de campos, que considerava apenas três categorias: emergentes, maduros e em declínio. A nova proposta de tipologia do campo emergente fortalece que as iniciativas de institucionalização sofrem riscos de descontinuidade imediata para contexto do empreendedor institucional.

Notou-se que os problemas enfrentados por esses EIV's são semelhantes no decorrer da construção de sua legitimidade e que tem por base a desinstitucionalização da estrutura vigente e o baixo grau de institucionalização dos polos varejistas. Mesmo o polo apresentado problemas de declínio e, consequentemente, abrindo a oportunidade para a desinstitucionalização dessas práticas, os EIV's encontraram diversas barreiras ao executarem o projeto de revitalização. Detectou-se que o EIV possuía um projeto de revitalização que buscava iniciar um processo de institucionalização dos polos varejistas, tentando, com isso, mobilizar o campo, a fim de buscar essa nova institucionalização (Phillips et al., 2004) ao explorar a retórica fundamentada na novidade. Questiona-se, diante disso, por qual razão encontraram dificuldades em legitimar a sua atuação diante da implantação de um projeto voltado a atingir benefícios coletivos? Nossa pesquisa demostra que tais fatores apresentados pela literatura foram insuficientes para responder tal questionamento. No entanto, nossa pesquisa ressalta que a falta de engajamento, orientação de mercado, senso de rede e influências culturais foram os ingredientes que faltaram para gerar o mínimo de institucionalização, capazes de gerar tais benefícios coletivos.

Em linha amarrada com David et al. (2013), corroboramos a afirmação de que atores que promovem novas formas organizacionais, em novos campos, dependem muito mais do que apenas a habilidade retórica. Retórica que foi uma das estratégias aplicada pelos EIV's no intuito de poder construir a sua legitimidade nos polos varejistas, muito embora não conseguiram avançar, de forma sustentável, perante a proposta de revitalização. De início, esses empreendedores não tinham coordenação, planejamento ou uma agenda em comum que visasse transformar o polo varejista antes de serem convocados para assumirem esse papel. Nesse contexto, para efetivar as mudanças institucionais, os EIV's precisaram de organização e recursos suficientes, além do campo, para que pudessem apresentar condições mínimas de institucionalização e que pudessem facilitar essa captação de recursos (Tolbert \& Zucker, 1983).

Nossa argumentação abre uma discussão em diversas vertentes envolta dessa temática, que versa sobre a construção da legitimidade em campos pré-emergentes, até então não explorada pela literatura. Tal propositura refere-se a quatro dimensões: (a) habilidades e condições do El no intuito de identificar o grau de institucionalização do campo, (b) maturidade dos atores, (c) estratégias para construção da legitimidade e (d) riscos de desvios. Observamos nessa pesquisa que, mesmo tendo um projeto de revitalização focado em reverter um processo de declínio, os varejistas não apresentam maturidade suficiente para endossarem o projeto de revitalização. Além disso, a baixa maturidade do campo foi um fator de insucesso na construção 
da legitimidade dos EIV's. O polo varejista apresentou características institucionais embrionárias, pré-emergentes. Portanto, a falta de um quadro institucional do polo varejista ajuda a explicar as dificuldades encontradas pelos EIV's na construção da sua legitimidade que almejava avançar em um projeto de revitalização em beneficio refletido em rede. A atuação desses empreendedores foi fundamentada na criatividade e em iclos de tentativa e erro. Não houve uma clareza e uma definição das melhores estratégias de abordagem, alinhamento de expectativas e análise do perfil dos varejistas. Por fim, não houve um planejamento coeso capaz de reduzir os ruídos no polo varejista e, com isso, garantir a construção da legitimidade dos EIV's.

Os resultados não confirmaram a expectativa de que empreendedores institucionais conseguem atuar e legitimar os seus projetos de desinstitucionalização em determinados campos, efetuando mudanças, assumindo uma posição dominante e conseguindo implementar mudanças por meio de articulação e mobilização de atores próximos, fatos estes amplamente discutidos na literatura (Battilana et al., 2009; Fligstein, 1997; Greenwood et al., 2002; Holm, 1995; Rao et al., 2000). A análise dos casos mostra que os resultados dos empreendedores espontâneos foram considerados superiores. Desta forma, é importante salientar que não necessariamente o convocado, com empréstimo de legitimidade de outras instituições externas ao seu campo, conseguirá avançar com sua agenda de mudança. Talvez os empreendedores institucionais varejistas convocados não tivessem o perfil adequado, característico dos empreendedores institucionais bem-sucedidos, ou a ausência de fragmentos de institucionalização talvez fosse tão intensa a ponto de dificultar a atuação dos empreendedores institucionais.

Além disso, não havia esquemas compartilhados no campo, que alimentassem os atores varejistas, enraizados no baixo engajamento, com baixa orientação de mercado, aspectos culturais e sem consciência de rede de colaboração, o que impediu o avanço do processo desinstitucionalização da estrutura vigente e influenciou negativamente a construção da legitimidade do EIV's. Aqui, reforçamos e contribuímos essa vertente, cuja atuação do El deve considerar e conciliar o grau institucional do campo e maturidade dos atores, de modo a definir as estratégias de legitimidade. Poucos estudos avançaram nesse processo de pré-atuação dos empreendedores institucionais, no sentido de gerar um estoque mínimo de legitimidade que pudesse garantir a sua atuação e, como há falta dessa abordagem, há influência e desvio de seu propósito institucional.

Assim, este estudo fornece uma série de contribuições para com as pesquisas futuras e pode apoiar novos estudos sobre a atuação efetiva do El em determinados campos. Cabe reforçar que, além de apresentar comportamentos de El e possuir um projeto relevante em benefício dos atores, devemos analisar antecipadamente a maturidade do campo e perfil dos atores para, posteriormente, delinear estratégias de construção de legitimidade.

Finalmente, a pesquisa possui também uma série de limitações. A primeira delas e a mais importante é a ausência de visão dos outros atores em relação a legitimidade dos EIV's e do projeto de revitalização. Compreender a visão desses autores ajudaria na complementação e validação dessa 
pesquisa, assim como o seu posicionamento no campo, de modo a gerar uma série de novas razões que ajudariam a explicar a falta de apoio na construção da legitimidade e quais estratégias estariam mais coerentes, para poder elevar o grau institucional nos polos varejistas. Torna-se necessário também aprofundar as pesquisas em novos campos em pré-formação, a fim de verificar outros fatores que contribuem para o sucesso ou insucesso da legitimidade do El. Por fim, apesar desses resultados, é necessário mais investigação sobre como construir instrumentos práticos que possibilitem os El's validarem gerencialmente suas estratégias no campo institucional, mensurando os seus resultados efetivos.

\section{Referências}

Ahmadjian, C. L., \& Robinson, P. (2001). Safety in numbers: Downsizing and the deinstitutionalization of permanent employment in Japan. Administrative Science Quarterly, 46(4), 622-654. https://doi.org/10.2307/3094826

Ahrens, T., \& Ferry, L. (2016). Institutional entrepreneurship, practice memory, and cultural memory: Choice and creativity in the pursuit of endogenous change of local authority budgeting. Management Accounting Research, 1-10. https://doi. org/10.1016/j.mar.2016.11.001

Aldrich, H. E., \& Fiol, C. M. (1994). Fools Rush in? The Institutional Context of Indsutry Creation. The Academy of Management Review, 19(4), 645-670. https:// doi.org/10.2307/258740

Amis, J., Slack, T., \& Hinings, C. R. (2004). The Pace, Sequence, and Linearity of Radical Change. Academy of Management Journal, 47(1), 15-39.

Anand, N., \& Peterson, R. A. (2000). When Market Information Constitutes Fields: Sensemaking of Markets in the Commercial Music Industry. Organization Science, 11(3), 270-284. https://doi.org/10.1287/orsc.11.3.270.12502

Balsas, C. L. (2000). City center revitalization in Portugal. Cities, 17(1), 19-31. http:// scholar.google.com/scholar?hl=en\&btnG=Search\&q=intitle:City+center+revitalizatio n+in+Portugal\#2

Battilana, J., Leca, B., \& Boxenbaum, E. (2009). How Actors Change Institutions: Towards a Theory of Institutional Entrepreneurship. The Academy of Management Annals, 3(1), 65-107. https://doi.org/10.1080/19416520903053598

Benbasat, I., Goldstein, D. K., \& Mead, M. (1987). Strategy in Studies of. MIS Quarterly, 11(3), 369-386. https://doi.org/10.2307/248684

Boxenbaum, E. (2004). For symposium : Perspectives on Institutional Entrepreneurship Academy of Management Annual Conference New Orleans , August 6-11, 2004 The Innovative Capacity of Institutional Entrepreneurs: A Reconstruction of Corporate Social Responsibility The Innova. Business.

Boxenbaum, E., \& Battilana, J. (2005). Importation as innovation: transposing managerial practices across fields. Strategic Organization, 3(4), 355-383. https://doi. org/10.1177/1476127005058996

Buhr, K. (2012). The Inclusion of Aviation in the EU Emissions Trading Scheme: Temporal Conditions for Institutional Entrepreneurship. Organization Studies, 33(11), 1565-1587. https://doi.org/10.1177/0170840612463324 
Caronna, C. A. (2004). The Misalignment of Institutional " Pillars ": Consequences for the U. S. Health Care Field. Journal of Health and Social Behavior, 45, 45-58.

Cook, I. R. (2009). Private sectorinvolvement in urban governance: The case of Business Improvement Districts and Town Centre Management partnerships in England. Geoforum, 4O(5), 930-940. https://doi.org/10.1016/j.geoforum.2009.07.003

Clemens, Elisabeth S., \& James M. Cook. 1999. "Politics and Institucionalism: Explaining Durability and Change." Annual Review of Sociology, 25(1),441-66.

Dacin, M. T., Goodstein, J., \& Scott, W. (2002a). Institutional theory and institutional change: Introduction to the special research forum. Academy of Management Journal, 45(1), 45-57. http://amj.aom.org/content/45/1/45.short

Dacin, M. T., Goodstein, J., \& Scott, W. R. (2002b). Institutional Theory and Institutional Change: Introduction to the Special Research Forum. Academy of Management Journal, 45(1), 43-56. http://www.jstor.org/stable/3069284

David, R. J. R., Sine, W. D. W., \& Haveman, H. A. H. (2013). Seizing opportunity in emerging fields: How institutional entrepreneurs legitimated the professional form of management consulting. Organization Science, 24(2), 356-377. https://doi. org/10.1287/orsc. 1120.0745

Davis, G., Diekmann, K., \& Tinsley, C. (1994). The Decline and Fall of the Conglomerate Firm in the 1980s: the Deinstitutionalization of an Organizational Form. American Sociological Review, 59(4), 547-570. https://doi.org/10.1017/ CBO9781107415324.004

Déjean, F., Gond, J.-P., \& Leca, B. (2004). Measuring the Unmeasured: An Institutional Entrepreneur Strategy in an Emerging Industry. Human Relations, 57(6), 741-764. https://doi.org/10.1177/0018726704044954

Denzin, N. K., \& Lincoln, Y. S. (1994). Handbook of qualitative research. Thousand Oaks: Sage Publications

DiMaggio, P. J., \& Powel, W. W. (1983). The iron cage revisited: Institutional isomorphism and collective rationality in orgnizational fields. American Sociological Review, 48, 147-160.

Dokmeci, V., Altunbas, U., \& Yazgi, B. (2007). Revitalisation of the Main Street of a Distinguished Old Neighbourhood in Istanbul. European Planning Studies, 15(1), 153-166. https://doi.org/10.1080/09654310601016788

Dorado, S. (2013). Small Groups as Context for Institutional Entrepreneurship: An Exploration of the Emergence of Commercial Microfinance in Bolivia. Organization Studies, 34(4), 533-557. https://doi.org/10.1177/0170840612470255

Dowling, J., \& Pfeffer, J. (1975). Organizational Legitimacy: Social Values and Organizational Behavior. The Pacific Sociological Review, 18(1), 122-136.

Eisenhardt, K. M. (1989). Building theories from case study research. Academy of Management Review, 14(4), 532-550. https://doi.org/10.2307/258557

Fligstein, N. (1997). Social skill and the theory of fields. American Behavioral Scientist, 40, 397-405. https://doi.org/0803973233

Fligstein, N., \& Mara-Drita, I. (1996). How to make a market: Reflections on the attempt to create a single market in the European Union. American Journal of Sociology, 102(1), 1-33. https://doi.org/10.1086/230907 
Fligstein, N., \& McAdam, D. (2011). Toward a general theory of strategic action fields. Sociological Theory, 29(1), 1-26. https://doi.org/10.1111/j.1467-9558.2010.01385.x

Garud, R., Hardy, C., \& Maguire, S. (2007). Institutional entrepreneurship as embedded agency: an introduction to the special issue. Organization Studies, 28(7), 957-969. https://doi.org/10.1177/0170840607078958

Garud, R., Jain, S., \& Kumaraswamy, A. (2002). Institutional entrepreneurship in the sponsorship of common technological standards : the case of Sun Microsystems and Java. The Academy of Management Journal, 45(1), 196-214.

Greenwood, R., \& Hinings, C. R. (1996). Understanding radical organizational change: Bringing together the old and the new institutionalism. Academy of Management Review, 21(4), 1022-1054.

Greenwood, R., \& Suddaby, R. (2006). Institutional entrepreneurship in mature fields: The big five accounting firms. Academy of Management Journal, 49(1), 27-48. https://doi.org/10.5465/AMJ.2006.20785498

Greenwood, R., Suddaby, R., \& Hinings, C. R. (2002). Theorizing change: the role of professional associations in the transformation of institutionalized fields. Academy of Management Journal, 45(1), 58-80. https://doi.org/10.2307/3069285

Guba, E. G., \& Lincoln, Y. S. (1994). Competing paradigms in qualitative research. In N. K. Denzin \& Y. S. Lincoln (Eds.). Handbook of qualitative research (pp. 105-117). London: Sage.

Hardy, C., \& Maguire, S. (2008). Institutional entrepreneurship. In R. Greenwood, C. Oliver, K. Sahlin, \& R. Suddaby (Eds.), Handbook of Organizational Institutionalism (pp. 198-217). London: SAGE

Hargadon, A. B., \& Douglas, Y. (2001). When innovations meet institutions: Edison and the design of the electric light. Administrative Science Quarterly, 46(3), 476-501. https://doi.org/10.2307/3094872

Hart, C., Stachow, G., \& Cadogan, J. W. (2013). Conceptualising town centre image and the customer experience. Journal of Marketing Management, 29(15-16), 17531781. https://doi.org/10.1080/0267257X.2013.800900

Hoffman, A. J. (1999). Institutional evolution and change: environmentalism and the U.S. Chemical Industry. The Academy of Management Journal, 42(4), 351-371.

Holm, P. (1995). The dynamics of institualization: transformation processes in Norwegian fisheries. Administrative Science Quarterly, 40(3), 398-422.

Jayanti, R. K., \& Raghunath, S. (2018). Institutional entrepreneur strategies in emerging economies: creating market exclusivity for the rising affluent. Journal of Business Research, 89(January 2016), 87-98. https://doi.org/10.1016/j.jbusres.2018.03.039

Koene, B. a. S. (2006). Situated human agency, institutional entrepreneurship and institutional change. Journal of Organizational Change Management, 19(3), 365-382. https://doi.org/10.1108/09534810610668364

Kupke, \& Valerie. (2004). Identifying the dimensions to retail centre image. Journal of Property Investment \& Finance, 22(4), 298-306. https://doi. org/10.1108/14635780410550858

Lawrence, T., Hardy, C., \& Phillips, N. (2002). Institutional effects of interorganizational collaborations: the emergency of Proto-Institutions. Academy of Management Journal, 45(1), 281-290. https://doi.org/10.2307/3069297 
Leca, B., Battilana, J., \& Boxenbaum, E. (2008). Agency and institutions : a review of institutional entrepreneurship. In HBS Working Paper (No. 08-096). https://doi. org/10.1111/j.1467-8683.2008.00685.x

Maguire, S., Hardy, C., \& Lawrence, T. B. (2004). Institutional entrepreneurship in emerging fields: HIV / AIDS treatment advocacy in Canada. The Academy of Management Journal, 47(5), 657-679.

Meyer, J., \& Rowan, B. (1977). Institutionalized organizations: formal structure as myth and ceremony. American Journal of Sociology, 83(2), 340-363. http://www. jstor.org/stable/2778293

Milchen, J. (2005). The benefits of doing business locally. American Institute of Business Alliances, Boseman, MT., 1-2. http://www.amiba.net/assets/files/pdfs/ benefits_doing_biz_locally.pdf

Miles, MB. \& Huberman, AM. (1994). Qualitative data analysis (2nd edition). Thousand Oaks, CA: Sage Publications.

Oliver, C. (1992). The antecedents of deinstitutionalization. Organization Studies, 13(4), 563-588. https://doi.org/10.1177/017084069201300403

Page, S., \& Hardyman, R. (1996). Place marketing and town centre management: Inew tool for urban revitalization. Cities, 13(3), 153-164. http://www.sciencedirect. com/science/article/pii/0264275196000029

Pettigrew, A. M. (1987). Theoretical, methodological and empirical issues in studying change. Journal of Mangement Studies, 420-426.

Pettigrew, A. M. (1990). Longitudinal field research on change: theory and practice. Organization Science, 1(3), 267-292. https://doi.org/doi: 10.2307/2635006

Phillips, N., Lawrence, T. B., \& Hardy, C. (2000). Inter-organizational collaboration and the dynamics of institutional fields. Journal of Management Studies, 37(1), 23-41. https://doi.org/10.1111/1467-6486.00171

Phillips, N., Lawrence, T. B., \& Hardy, C. (2004). Discourse and institutions. Academy of Management Review, 29(4), 636-652. https://doi.org/10.5465/AMR.2004.14497617

Presti, J. (2003). Neighborhood Business District Analysis: Pioneer Square Business Improvement Area, Seattle [University of Washington]. In professional project submitted in partial fulfillment of .... http://scholar.google.com/scholar?hl=en\&btnG= Search\&q=intitle:Neighborhood+Business+District+Analysis+:+Pioneer+Square+Bu siness+Improvement+Area+,+Seattle\#0

Pryor, S., \& Grossbart, S. (2005). Ethnography of an American Main Street. International Journal of Retail \& Distribution Management, 33(11), 806-823. https:// doi.org/10.1108/09590550510629400

Qureshi, I., Kistruck, G. M., \& Bhatt, B. (2016). The enabling and constraining effects of social ties in the process of institutional entrepreneurship. Organization Studies, 37(3), 425-447. https://doi.org/10.1177/0170840615613372

Rao, H., Morrill, C., \& Zald, M. N. (2000). Power plays: how social movements and collective action create new organizational forms. Research in Organizational Behavior, 22, 237-281. https://doi.org/10.1016/S0191-3085(00)22007-8

Ruef, M., \& Scott, W. R. (1998). A multidimensional model of organizational legitimacy: hospital survival in changing institutional environments. Administrative Science Quarterly, 43(4), 877-904. https://doi.org/10.2307/2393619 
Scott, W. R. (1987). The adolescence of theory institutional. Administrative Science Quarterly, 32(4), 493-511.

Scott, W. R. (2008). Lords of the dance: professionals as institutional agents. Organization Studies, 29(2), 219-238. https://doi.org/10.1177/0170840607088151

Seo, M.-G., \& Creed, W. E. D. (2002). Institutional contradictions, and institutional change: a dialectical. Management, 27(2), 222-247.

Singh, J. V, Tucker, D. J., \& House, R. J. (1986). Organizational legit- imacy and the liability of newness Robert J. House. Administrative Science Quarterly, 31(2), 171193. http://www.ncbi.nlm.nih.gov/pubmed/22157681

Smith, D. L., Hoersch, A. L., \& Gordon, P. R. (1995). Problem-Based Learning in the undergraduate Geology classroom. 43, 149-152.

Stål, H. I., Bonnedahl, K. J., \& Eriksson, J. (2014). The challenge of introducing low-carbon industrial practices: institutional entrepreneurship in the agri-food sector. European Management Journal, 32(2), 203-215. https://doi.org/10.1016/j. emj.2013.06.005

Suddaby, R., \& Greenwood, R. (2005). Rhetorical strategies of legitimacy. Administrative Science Quarterly, 50(1), 35-67. https://doi.org/10.2189/asqu.2005.50.1.35

Teller, C. (2008). Shopping streets versus shopping malls-determinants of agglomeration format attractiveness from the consumers' point of view. Review of Retail, Distribution and Consumer Research, 18(4), 381-403. http://www.tandfonline. com/doi/abs/10.1080/09593960802299452

Teller, C., Elms, J. R., Thomson, J. A, \& Paddison, A. R. (2010). Place marketing and urban retail agglomerations: an examination of shoppers' place attractiveness perceptions. Place Branding and Public Diplomacy, 6(2), 124-133. https://doi. org/10.1057/pb.2010.11

Teller, C., \& Reutterer, T. (2008). The evolving concept of retail attractiveness: what makes retail agglomerations attractive when customers shop at them? Journal of Retailing and Consumer Services, 15(3), 127-143. https://doi.org/10.1016/j. jretconser.2007.03.003

Tolbert, P., \& Zucker, L. (1983). Institutional sources of change in the formal structure of organizations: the diffusion of Civil Service Reform. Administrative Science Quarterly, 28(1), 22-39. http://www.jstor.org/stable/2392383

Van Bockhaven, W., Matthyssens, P., \& Vandenbempt, K. (2015). Empowering the underdog: Soft power in the development of collective institutional entrepreneurship in business markets. Industrial Marketing Management, 48, 174-185. https://doi. org/10.1016/j.indmarman.2015.03.020

Wade-Benzoni, K. A., Hoffman, A. J., Thompson, L. L., Moore, D. A., Gillespie, J. J., \& Bazerman, M. H. (2002). Resolution in ideologically based negotiations: the role of values and institutions. Academy of Management Review, 27(1), 41-58.

Ward, K. (2007). Creating a personality for downtown: business improvement districts in Milwaukee. Urban Geography, 28(8), 781-808.

Wicks, D. (2001). Institutionalized mindsets of invulnerability: differentiated institutional fieldsand the antecedents of organizational crisis. Organization Studies, 22(4), 659-692. https://doi.org/10.1177/07399863870092005 
Revista Eletrônica de Ciência Administrativa

Yin, R. K. (2009). Case study research: design and methods (4th Ed.). Thousand Oaks, CA: Sage.

Zelditch, M. (2001). Processes of legitimation: recent developments and new directions. Social Psychology Quarterly, 64(1), 4-17. https://doi.org/10.2307/3090147

Zimmerman, M. a., \& Zeitz, G. J. (2002). Beyond survival: achieving new venture growth by building legitimacy. Academy of Management Review, 27(3), 414-431. https://doi.org/10.5465/AMR.2002.7389921

Zucker, L. (1987). Institutional theories of organization. Annual Review of Sociology, 13, 443-464. http://www.jstor.org/stable/2083256 